This item is the archived peer-reviewed author-version of:

\title{
Learning in times of dynamic complexity through balancing phenomenal qualities of
} sensemaking

\section{Reference:}

Guiette Alain, Vandenbempt Koen.- Learning in times of dynamic complexity through balancing phenomenal qualities of sensemaking

Management learning: the international journal for managerial and organizational learning and development - ISSN 1350-5076 47:1(2016), p. 83-99

Full text (Publishers DOI): http://dx.doi.org/doi:10.1177/1350507615592112 


\title{
Learning in times of dynamic complexity through balancing phenomenal qualities of sensemaking
}

\author{
Alain Guiette ${ }^{1}$ \\ University of Antwerp, Belgium. \\ Koen Vandenbempt \\ University of Antwerp, Belgium.
}

\begin{abstract}
This article provides the scaffolding for a more holistic approach towards sensemaking and learning by arguing that learning to navigate dynamic complexity requires a sensemaking lens grounded in different phenomenal qualities. Widening the aperture of the sensemaking perspective, we advance a more holistic and integrative approach towards sensemaking and learning, by taking sensemaking's processual and temporal nature seriously. Inspired by phenomenological work of Heidegger's three modes of being-in-the-world - 'availableness', 'occurentness', and 'involved thematic deliberation' - we argue that learning 'becomes' through the continuous re-enactment of sensemaking grounded in absorbed, detached, and mindful coping, respectively. It follows that learning in times of dynamic complexity is reappraised as occurring during the continuous re-enactment of sense being made at the crossroad of detached, absorbed and mindful coping, in an effort to weather dynamic complexity at the intersection of order and disorder by both reducing and exploring equivocality.
\end{abstract}

\section{Keywords}

Sensemaking, learning, processual perspective, phenomenology, mindfulness.

\section{${ }^{1}$ Corresponding author:}

Alain Guiette, Department of Management, Faculty of Applied Economics, University of Antwerp, Prinsstraat 13, 2000 Antwerp, Belgium, Email: alain.guiette@uantwerpen.be 


\section{Introduction}

The presumed proverb 'May you live in interesting times!' can be interpreted as both a curse or a blessing. On the one hand it assumes an undesirable quality of complexity and struggle coupled with the desire to control and reduce uncertainty. On the other hand, it encapsulates a sense of novelty, innovation and progress for the good, and a desire to embrace new and interesting times. No matter whether these 'interesting times' are labelled as dynamic complexity (Farjoun, 2010), emerging complexity (Scharmer, 2009), equivocality (Weick, 1979), ambiguity (March \& Olsen, 1975), tangled worlds (Hernes, 2007), messiness (Law, 2004), or unpredictable equivocality (Colville, Brown, \& Pye, 2012), the urge to 'manage' and 'control' this complexity predominates.

In order to make sense of this complexity ${ }^{2}$, sensemaking dynamically constructs intersubjective meaning of phenomena through cycles of interpretation and enactment (Maitlis \& Christianson, 2014) to create order and reduce equivocality. Organisational actors learn to make sense of complexity in the coming together of frames and assumptions of past organizing against unfolding cues from an emergent present (Clegg, Kornberger, \& Rhodes, 2005; Colville, Hennestad, \& Thoner, 2014). It is precisely this sensemaking, captured between 'thinking backward' and 'living forward' that poses particular challenges to sensing, interpreting and enacting organisational processes in times of dynamic complexity. Indeed, how can inflexible and myopic frames inspired by past organizing stop filtering the emergent present for making sense of future organizing? How can organisations stop to unconsciously reduce the confusing 'sea of possibilities' (James, 1956) to pre-established categories that ignore any manifestation of novelty? And, in the first place, how can learning occur if emerging phenomena are dismissed at the outset from our sensemaking funnel by frames from the past?

The dominant approach in tackling these sensemaking and learning challenges consists of reducing equivocality and shifting the thinking-acting balance towards more acting (Colville, 1994; Colville, et al., 2012; Colville, Pye, \& Brown, 2013). Through 'simplexity' (Colville, 1994), the fusing of complexity of thought with simplicity of action, sensemaking in complex times is argued to balance more towards equivocality-reducing action. Emphasizing action over thought during sensemaking diminishes the power of interpretive frames from the past when interpreting events of the present (Colville, et al., 2012): "when the flux is in flux, organizing and sensemaking should be more weighted to the action wing of the dialectic" (Colville, et al., 2012, p. 9).

\footnotetext{
${ }^{2}$ For the purpose of this article, we define complexity from an observer-dependent perspective: "the complexity of a system, as seen by an observer, is directly proportional to the number of inequivalent descriptions of the system that the observer can generate (Casti, 1986, 1994). The more inequivalent descriptions an observer can produce, the more complex the system will be taken to be." (Tsoukas \& Hatch, 2001, p. 986). Equivocality, on the other hand, is linked to the simultaneous existence of multiple - and sometimes conflicting - underlying meanings or interpretations of phenomena, whereby additional information does not resolve the degree of equivocality (Daft \& Macintosh, 1981; Weick, 1979).
} 
The objective of this article is to further refine this line of thought by bringing different qualities of sensemaking in the picture. Rather than representing sensemaking as a dualism between action and thought and focusing more on action in times of increased complexity, we advance the idea that sensemaking in complex times occurs through different phenomenal groundings. We hereby adopt a processual perspective which "invites us to acknowledge, rather than reduce, the complexity of the world" (Hernes \& Maitlis, 2010, p. 3): How can learning occur that embraces rather than reduces equivocality? How can organisational actors drop their habitual way of interpreting and making sense of complexity?

To address these questions, we argue that learning under conditions of dynamic complexity occurs through widening the aperture of the sensemaking perspective by taking in an interpretative phenomenological approach (Chia \& Holt, 2006; Holt \& Cornelissen, 2013; Sandberg \& Tsoukas, 2011; Tsoukas, 2010; Yanow \& Tsoukas, 2009) that takes process and temporality seriously.

Inspired by Heideggerian phenomenology with its three modes of engagement with the world, we advance three phenomenal qualities of sensemaking: sensemaking grounded in 'absorbed coping' ('availableness' or 'ready-to-hand'), sensemaking grounded in 'detached coping' ('occurentness' or 'present-at-hand'), and sensemaking grounded in 'mindful coping' ('involved thematic deliberation' or 'unready-to-hand'). Rather than copying the past into the present, sensemaking under dynamic complexity needs to bring the emerging future into the present by reflexively making sense of cues in the 'here and now'. Organisational actors that reflexively make sense of unfolding cues 'in-the-moment' become aware of the dissonance induced by an outdated 'interpretive apparatus'. As such, learning 'becomes' through the continuous re-enactment of sensemaking grounded in detached, absorbed and mindful coping and by transcending the orderdisorder conundrum (Clegg, et al., 2005) and the organizing-disorganizing oxymoron (Weick \& Westley, 1999).

This article provides the scaffolding for a more holistic approach towards sensemaking and learning by arguing that learning to navigate dynamic complexity requires a sensemaking lens grounded in different phenomenal qualities. We hereby elaborate the argument of Jordan, Messner, and Becker (2009, p. 466) that "a comprehensive understanding of learning in organizations would benefit from an analysis of different forms of reflection and mindfulness and of the ways in which these forms interact." and the call of Colville, et al. (2012, p. 9) that "we need observing that is more mindful, concepts that are more refined and constraints on sharing that are less tight". Although authors have already referred to reflection and mindfulness to better understand how learning occurs (Jordan, et al., 2009; Keevers \& Treleaven, 2011), we emphasize the onto-epistemological shift advocated by processual perspectives and build upon Heideggerian inspired interpretive phenomenology to explicitly explore how learning occurs through sensemaking of dynamic complexity. From this perspective, learning occurs "in the juxtaposing of order and disorder, frames of past learning and cues of present action." (Colville, et al., 2014, p. 216). 
We contribute to the management learning and sensemaking literatures by reappraising the link between sensemaking and learning, arguing that sensemaking is grounded in different epistemic assumptions and coping styles. Infusing different modes of relating to the world in the sensemaking perspective thereby transcends its predominant retrospective temporal orientation as well as the continuity-episodic tension that limits the further investigation of a more holistic and integrative sensemaking perspective. As such, we add further refinement to the simplexity line of thought by (1) elaborating on a broader temporal perspective of sensemaking that is grounded in the past, present and emerging future rather than being predominantly retrospective, (2) taking in the true processual nature of sensemaking and refining its continuity-episodic paradox by demonstrating that sense is continually re-enacted at the intersection of different phenomenal qualities, and (3) reappraising learning as occurring during this continuous re-enactment of sensemaking at the crossroad of detached, absorbed and mindful coping, in an effort to both reduce and explore equivocality. The essential point is that by broadening the aperture of the sensemaking perspective inspired by Heidegger's three modes of being-in-the-world, we address a central tension in simplexity - "the ways in which people redeploy concepts in order to ward off blind perceptions, and redirect perceptions to ward off empty conceptions." (Weick, 2012, p. 151) - and provide a reappraisal of the link between learning and sensemaking under conditions of dynamic and emerging complexity. In sum, responding to and engaging with dynamic complexity through detached, absorbed, and mindful coping enables the occurrence of learning through the dynamic equilibrium of phenomenal qualities of sensemaking.

This article is organised as follows. In light of recent sensemaking reviews, we emphasize the processual and temporal nature of sensemaking and learning, and advance interpretative phenomenology to refine the relationship between sensemaking and learning. Then we explain how Heidegger's three modes of engagement with the world ground different qualities of organisational sensemaking: 'availableness' and sensemaking grounded in 'absorbed coping', 'occurentness' and sensemaking grounded in 'detached coping', and 'involved thematic deliberation' and sensemaking grounded in 'mindful coping'. We finally argue how learning occurs at the crossroad of sensemaking grounded in different phenomenal qualities in order to deal with equivocality in complex times. 


\section{Revisiting sensemaking and learning under dynamic complexity}

Recent review articles (Hernes \& Maitlis, 2010; Holt \& Cornelissen, 2013; Maitlis \& Christianson, 2014; Sandberg \& Tsoukas, 2014) have reaffirmed the prominence of the sensemaking perspective and its influence in organisation and management theory since the publication of Weick's seminal work (Weick, 1969, 1979, 1995; Weick, Sutcliffe, \& Obstfeld, 2005). Framed in cognitive, social, and discursive processes, sensemaking is defined as "a process, prompted by violated expectations, that involves attending to and bracketing cues in the environment, creating intersubjective meaning through cycles of interpretation and action, and thereby enacting a more ordered environment from which further cues can be drawn." (Maitlis \& Christianson, 2014, p. 67). In relation to learning, sensemaking has been advanced as important in both crisis and more conventional contexts, and a critical process in environments that are uncertain, ambiguous and where problem-spotting is as challenging as problem-solving (Maitlis \& Christianson, 2014).

It follows that in 'interesting times' fused with the emergence of phenomena deemed thus far unimaginable, the tension between requisite variety and Weick's (1979) call for 'complicated understanding' on the one hand, and the fact that "we act our way into meaning by keeping it simple" (Colville, et al., 2012, p. 9) on the other hand, appears larger than ever. As a matter of fact, the tension between complicating yourself and keeping it simple, is not only a quantitative conundrum - i.e. more complexity of thought and less complexity of action (Colville, et al., 2012) - though also a qualitative balance in terms of different qualities of thinking and action, and thus different qualities of sensemaking. In light of this tension, and the link between sensemaking and learning, two issues appear particularly pertinent.

First, whereas the above mentioned definition of sensemaking hints at the temporal interconnectivity of past, present and future, the retrospective nature of sensemaking still predominates. Considering that "meaning (...) is made in an ongoing present in which past experience is projected upon possible futures" (Hernes \& Maitlis, 2010, p. 27), mental models and cognitive representations from the past are replicated in order to interpret phenomena and cues from the present. This implies that 'enaction' is driven by representations from the past which are not based on the experience from the now. Although discrepancies between expectations and 'reality' - considered as major triggers for sensemaking (Maitlis \& Christianson, 2014) - may appear to be related to the living present, these expectations remain projected images of a possible future constructed through representations from the past. As a result, future perfect thinking remains anchored in a predominantly retrospective temporal orientation given that they are "grounded in hitherto taken-for-granted beliefs" (Sandberg \& Tsoukas, 2014, p. 4). Along these lines, for example, Wiebe (2010) argues for a broader temporal orientation - 'temporal sensemaking' - taking serious the temporal embeddedness of sensemaking in past, present and future, whereas Holt and Cornelissen (2013, p. 1) call for considering that "sense (is) being governed by exposure to unknown possibility rather than retrospective assessment".

Second, as highlighted by Sandberg and Tsoukas' (2014) review, sensemaking seems to be predominantly 'activated' by interrupted expectations, emphasizing a rather episodic nature of 
sensemaking. This presumes that sensemaking is triggered by disruption or breakdown, and can subsequently be isolated as an independent phenomenon. Chunking sensemaking in isolated streams is however more inspired by representational convenience rather than phenomenological relevance. This is not only the case for separating creation, interpretation and enactment subprocesses (Sandberg \& Tsoukas, 2014), but also for distinguishing between sensemaking triggered by breakdowns or interruptions on the one hand and mere ongoing sensemaking of the multiplicity of phenomena on the other hand. From an interpretative phenomenological perspective, disruptions or breakdowns pull actors from immersion to detachment (Holt \& Cornelissen, 2013; Holt \& Sandberg, 2011; Yanow \& Tsoukas, 2009), which does not mean that sensemaking is 'triggered' during this transition, rather, that sensemaking shifts in terms of phenomenological quality by entering overtly in the meaning making arena. Therefore, positing sensemaking as 'triggered' by breakdowns or interruptions of various magnitude seems to be phenomenologically inconsistent with sensemakers' experienced reality.

Elaborating on this line of thinking in terms of learning, cognitively oriented episodic perspectives on sensemaking aim at "restoring cognitive order" (Sandberg \& Tsoukas, 2014, p. 10) once the disruption has been made sense of. This 'restoring' of the cognitive order somehow dismisses the ability to learn in the sense that stability is interrupted and then restored to its original position. From an interpretive phenomenological perspective, viewing sensemaking as a continuous process with episodic fluctuations, cognitive order is not restored sensu strictu, rather, 're-enacted' whereby the cognitive order after the disruption if qualitatively different from the order before the disruption due to the lived experiences during the disruption. It is precisely that learning occurs through these re-enactment processes during continuously shifting back and forth between different phenomenal qualities of sensemaking. In other words, learning is "found in the juxtaposing of order and disorder, frames of past learning and cues of present action" (Colville, et al., 2014, p. 216), as well as in the tension between reducing and exploring equivocality, or simplifying and complicating understanding. It is at the intersection of different (dis)orders that learning occurs (Clegg, et al., 2005).

March (1991) already alluded in the exploitation-exploration conundrum that learning adopts different orders or different qualities and that 'optimal' learning occurs at the juxtaposing of order and disorder, i.e. when order and disorder are present simultaneously. Weick and Westley (1999, p. 196) add that learning "resides in the quality and the nature of the relationship between levels of consciousness within the individual, between individuals, and between the organization and the environment". In this article we elaborate on the occurring of learning in situations of simultaneous order and disorder whereby the quality of learning is linked with the level of consciousness of the individual in terms of his mode of engagement with the world. Taking the underlying epistemic context of sensemaking seriously (O'Leary \& Chia, 2007; Sandberg \& Tsoukas, 2014), this article proposes to widen the temporal and phenomenal repertoire of sensemaking by bringing to the fore three different phenomenal qualities of sensemaking. 


\section{Phenomenal qualities of sensemaking}

If we take the processual and temporal dimensions of sensemaking seriously, sensemaking is grounded in different qualities whereby learning occurs at their coming together. In order to shape these different phenomenal qualities of sensemaking, we rely on Heidegger's three modes of engagement with the world (Chia \& Holt, 2006; Dreyfus, 1991; Heidegger, 1926/2010), which also builds on different temporal dimensions of sensemaking (see Table 1). Heidegger pointed at different modes of engaging with the world - immersion, involved thematic deliberation and theoretical detachment - based on 3 ways in which the world may show itself to a being who is active in it: availableness, occurentness, and involved thematic deliberation.

INSERT TABLE 1 HERE

Along these lines, learning occurs at the nexus of living forward (absorbed coping) and understanding backward (detached coping) in the present moment (mindful coping). This 'in betweenness' enables organisations to discover and learn to make sense of the complexity that emerges in local contexts: "what is in between is where the real action is" (Cooper \& Law, 1995, p. 245). Weick (2003, p. 468) elaborates on this precise point by referring to Heidegger's unready-to-hand moments or involved thematic deliberation: "The crucial point is that the potential for better theorizing lies in closer scrutiny of those moments where backward and forward views meet." In the next three sections, availableness, occurentness and involved thematic deliberation, are leveraged as 'models of the world' (March, 1981) to define three coping styles that determine actors" "responsiveness to circumstances" (Chia \& Holt, 2006, p. 648) and subsequently fuel different phenomenal qualities of sensemaking that determine how sense or meaning is enacted and learning takes place.

\section{Availableness: Sensemaking grounded in 'absorbed coping'}

Availableness, our 'natural' mode of being in the world according to Heidegger, represents a mode of awareness of total immersion and unintentional absorption in the world prior to any deliberate action and mental presentation, a mode of 'dwelling' among readily available interiorised objects (Chia \& Holt, 2006; Heidegger, 1926/2010). Heidegger argues that we engage in the world guided by an 'engaged familiarity' (Blattner, 2006; Heidegger, 1926/2010). Being immersed in the world represents what Heidegger coined absorbed coping: "a spontaneous response not mediated by mental representations, which enables one to get around in the world, flexibly responsive to a situation as it unfolds" (Yanow \& Tsoukas, 2009, p. 1350). Actors are subsidiarily aware of their knowing and practicing, without being self-aware (Dreyfus, 1991). Absorbed coping is thus characterised by reflection-in-action and subject-object wholeness that is discriminative to being fully immersed in the local context. Immersed in subject-object wholeness, chronological-physical separation between reflection and action is low, as practitioners operate within their action-presence. Absorbed coping is characterised by gut 
feeling, following one's intuition as to what action is most appropriate, acting upon reality as it unfolds without questioning what the most appropriate action may be, not even realizing that this chain of actions has been followed. Absorbed coping occurs, for example, while being immersed in teaching a class of motivated students, conducting a spontaneous and lively conversation with friends, preparing your favourite recipe for a sumptuous meal, or going for your daily run in the park, as long as one remains 'absorbed' or in 'flow' (Csikszentmihalyi, 1992).

Based on a direct engagement with the world, sensemaking grounded in absorbed coping is 'driven' by what Bourdieu (1990) called 'habitus': “unconsciously acquired, culturally shaped habits of acting; a modus operandi that, though latent and visible, nevertheless plays an active role in shaping individual choices and strategic action." (Chia \& Holt, 2009, p. 23). From this perspective 'organizing' is perceived as something immanent, "it unfolds through everyday practical coping actions." (Chia \& Holt, 2006, p. 637) and a temporality of 'coming into present of emerging futures' (Stacey, 2011). In this context, sensemaking aims at replacing a conceptual order by a perceptual order. This requires nevertheless direct perceptual access to the unfolding micro-processes of organizing, denying the existence of pre-existing maps instructing which road to walk, thereby "reaching out into the unknown and developing and incomplete but practically sufficient comprehension of the situation in order to cope effectively with it." (Chia \& Holt, 2009, p. 159).

Sensemaking therefore, is not a by-product of deliberate and intentional actions, but the result of locally embedded initiatives that emerge spontaneously along the way: perceptions are enacted dynamic products of our active minds. Sensemaking thus automatically unfolds in a context of dynamism and equivocality, whereby sense is continually re-made based upon absorption in unfolding reality. Absorbed coping entails a feeling of comfort in situations of uncertainty, mystery, incompleteness and doubt; without clinging to controlling mechanisms and representational tools (Chia, 2013) - which is, for example, illustrated by Dreyfus and Dreyfus (2005) in the development of expert performance.

\section{Occurentness: Sensemaking grounded in 'detached coping'}

Occurentness represents a mode of being in the world that involves detachment between individual and phenomenon: "things and events force an actor immersed in his/her performance to become a reflective observer who self-consciously stands back and intentionally assigns identities, meanings, functions and causes both to him/herself and to phenomena around." (Chia \& Holt, 2006, pp. 641-642). As such, occurentness arises when availableness breaks down and intentional deliberate reflection takes over based on mental representations of the world, inducing a phenomenal quality of 'detached coping'. This mode of coping accentuates the intentionality of organisational actors to act according to representations of organisational reality, presuming a relationship of detachment between organisational actors and a pre-existing world out there, a relationship mediated by symbols, routines, rules, and procedures. Detached coping solicits action through mental representations of an external reality by means of deliberate intentionality 
and purposeful action (Chia \& Holt, 2006). Detached coping occurs, for example, by assessing your diet based on caloric intake, measuring performance solely in terms of revenues, rating a hotel stay based on its stars, relying for 100 percent on your GPS while driving, in short by responding to circumstances in a highly representational way, confusing the representation for what it aims to represent.

Detached coping is characterised by thematic intentionality and analytical, theoretical reflection (Yanow \& Tsoukas, 2009). Based on this representational awareness, organisational actors reflect intentionally on their actions either anticipatively or retrospectively. Reflection occurs 'on action' rather than 'in action', and typically out of the action-presence, i.e. a high chronological-physical separation of action and reflection (Schön, 1983). Detached coping is furthermore characterised by a complete subject-object separation that is decontextualised from what is happening 'out there'.

Sensemaking based upon detached coping thus considers equivocality to be exceptional, requiring intentional intervention by controlling - 'managing' - and reducing ambiguity and complexity along the journey. Organisational processes get chopped in a series of steps to achieve, measured by performance indicators that are supposed to represent the alignment of the organisation's performance with the intended plan. Underpinned by what Whitehead (2010) labelled the 'fallacy of misplaced concreteness' (the belief that things exist as isolated systems), the illusion is created of an independently existing social reality that can adequately be represented by the construction of organisational typologies (Chia, 1996a). This fosters the selective filtering and reduction of perceptual phenomena or concrete experiences into preexisting conceptual categories to make sense of lived experience (Weick, et al., 2005).

Sensemaking grounded in detached coping is heavily set in an ideology of representationalism (Chia, 1996a) whereby permanence of phenomenal experiences is advocated, through the use of underlying conceptual grammars for organizing the world (O'Leary \& Chia, 2007) and subject to generic subjectivity (Allard-Poesi, 2005; Weick, 1979). According to this perspective, sensemaking occurs "to accurately describe and represent reality as it is in itself" (Chia, 1996a, p. 2) whereby observer and observed are clearly separated. Equivocality is consequently seen as a necessary evil that requires to be controlled and eliminated by granting representational knowledge claims the status of absolute reality. Sensemaking grounded in detached coping operates under a conceptual order that filters experience through precast concepts and mental models whereby we "selectively reduce and make more comprehensively manageable our lived experiences" (Chia, 1996b, p. 39)

\section{Involved thematic deliberation: sensemaking grounded in 'mindful coping'}

A third framing of sensemaking is based on 'involved thematic deliberation' as mode of engaging with the world: "a mode of engagement that involves both immersion in practice and deliberation on how it is carried out" (Sandberg \& Tsoukas, 2011, p. 344). This mode of involved focusing is characterised by involvement in practical activity (Dreyfus, 1991), whereby deliberate attention is 
given to our actions. In other words, the quality of awareness of deliberate attention remains dependent on being engaged in activity, what could be referred to as 'reflection-in-practice' (Schön, 1983) or 'inquiry' (Dewey, 1910/1997). In this mode, awareness is brought intentionally to attending the task at hand under a subject-object wholeness. Organisational actors reflect on their doings both in action and in action presence. It represents a mode of coping that Yanow and Tsoukas (2009) have identified as 'deliberate coping' in a context of mild temporary breakdowns, whereby the chronological-physical separation between reflection and action is low. Involved thematic deliberation and its associated 'unreadiness-to-hand' (Heidegger, 1926/2010) mode of being in the world, represents an important mode of awareness in terms of learning: "The category of the unready to hand, then, is a category that makes sense relative to our capacities and skills, that is, relative to our understanding. The unready-to-hand is whatever challenges our abilities and forces us to bear down on it, rather than on the work to be accomplished" (Blattner, 2006, p. 58).

Building on the 'reflexive turn' in organisation studies and management learning (Cunliffe, 2002, 2004; Cunliffe \& Easterby-Smith, 2004; Reynolds, 1998; Yanow \& Tsoukas, 2009; Zundel, 2013) emphasizing 'reflection-in-action' (Cunliffe, 2004; Jordan, et al., 2009; Schön, 1983; Yanow \& Tsoukas, 2009) or 'real-time reflexivity' (Weick, 2002) brings us to the theme of mindfulness. Making sense of complexity in a reflexive way calls for a practitioner coping style that is grounded in in-the-moment reflexivity, that is non-judgmentally aware of what is going in, that is - in other worlds - mindful.

Despite Weick's ground-breaking work on collective conceptualizations of mindfulness (Weick, Sutcliffe, \& Obstfeld, 1999), mindfulness' intellectual legacy has permeated management learning to a limited extent only, exceptions including Hernes and Irgens (2013), Jordan, et al. (2009), and Ramsey (2014). Kabat-Zinn defines mindfulness as "the awareness that emerges through paying attention on purpose, in the present moment, and nonjudgmentally to the unfolding of experience moment by moment." (Kabat-Zinn, 2003, p. 145). This definition highlights three essential elements for the purpose of our discussion: (1) paying deliberate attention, (2) the unfolding experience of the present moment, and (3) a nonjudgmental or deconceptualised quality of bare attention. The latter quality decouples perception from cognition and inhibits habitual or conceptual responsivity. Mindfulness is about "the relentless cultivation of an ability to see clearly and in a pristine way; to develop an 'innocence of the eye' which is able to see things as they are without prejudice" (Chia, 2013, p. 16).

Sensemaking based on 'mindful coping' thus raises awareness of the intrinsic uncertainty of organizing, while attending to weak cues and unexpected events with discriminatory detail (Weick, et al., 1999). Mindful coping takes micro-processes and the equivocal and dynamic nature of organizing seriously, by 'anomalizing' expectations. Furthermore, mindful coping overcomes simplifications, 'pre-interpretation', and blind spots created by these expectations. By surfacing taken-for-granted assumptions, mindful coping prevents shifting from perceptual processing to conceptual processing and in applying irrelevant mental frameworks to novel situations. As Tsoukas and Chia (2002, p. 571) attest: "Only a direct perception of reality will 
enable one to get a glimpse of its most salient characteristics". Sensemaking grounded in 'mindful coping' interrupts automatic patterns of conditioned behavior whereby practitioners become aware of their predominant detachment in making sense of complexity (Maturana \& Varela, 1992; Varela, Rosch, \& Thompson, 1992). Mindful coping is displayed during improvising arguments as a discussion unfolds, during moments of 'not knowing' midst making decisions, when intuitively deciding to change course during teaching, or when choosing to halt the execution of an action that does not feel right.

Making mindfully sense of dynamic complexity fosters a nonjudgmental interpretation of the unfolding of organisational phenomena and allows the underlying complex interdependent practices of organizing to unfold 'as they are' (perceptually) rather than being immediately reified to state-like conceptualizations. Through practical experience that is based on intellectual naivety or 'learned ignorance' (Chia \& Holt, 2009), organisational actors focus their attention to the lived reality. Mindful coping refers to what Matsushita (1994/2002) defined as 'Sunao mind': "an 'untrapped mind' able to 'look at things as they are at that moment' without bias or preconception and to then adapt effectively to the ever-changing circumstances it finds itself in. (...) it enables us to perceive the real state of all things in society' thereby enabling wise decisions and actions to be made in the conduct of human affairs." (Chia, 2013, p. 16). On another note mindful coping fosters the integration of the experienced living present in light of a greater wholeness of being in the world, as such integrating parts and wholes - what Heidegger referred to as a "referential totality" (Hernes, 2014, p. 118) 


\section{Reappraising sensemaking and learning for interesting times}

The reappraisal advanced shifts the emphasis on the 'in-betweenness' in sensemaking and learning: learning happens in-between the continuous sensemaking episodes grounded in detached, absorbed and mindful coping. If learning is viewed as enabling "a dynamic appreciation of organizational life" (Clegg, et al., 2005, p. 147) rather than something that is done to organisations, then this dynamic appreciation is realised at the intersection of different phenomenal qualities of sensemaking. Just like organizing "is a process of increasing complexity and reducing it; ordering and dis-ordering” (Clegg, et al., 2005, pp. 153, emphasis in original), sensemaking is more than just a process to reduce equivocality or restore disruptions: it implies navigating interdependent, and often contradictory, phenomenal qualities of experiencing the world. It is precisely this navigation process and acknowledgement of coexistence that enables learning, and eventually allows organisation to take place. Whereas organisation oscillates between order and noise, disorder and harmony, complexification and simplification, deconstruction and reconstruction, deterritorialisation and reterritorialisation, or between a "headfirst dive into chaos" and "stabilized installation in order" (Clegg, et al., 2005, p. 147), so does learning occur at the interstices of unfolding tensions and dynamic equilibria between sensemaking grounded in detached, absorbed and mindful coping (see Figure 1).

This reading provides a perspective on sensemaking that is less focused on being triggered by violated expectations and more focused on the living present of individuals, making sense of their experiences on the go. Especially in 'interesting times' of high volatility, uncertainty, complexity and ambiguity, the temporal dimension of sensemaking becomes pivotal given that the past is a poor predictor of emerging futures. Emphasizing the phenomenal qualities of sensemaking places a premium on the world as such, on the individual experiencing the living present while being in the world and being open to potential emerging futures that actualize along the road, irrespective of learnings from the past and consequently allowing learning to occur in the presence of the now.

INSERT FIGURE 1 HERE

Bringing mindful coping in the detachment-immersion duality and the simplexity line of thought as a third quality of sensemaking is critical in order to emphasize the living concreteness of organisational life: "An answer to avoiding misplaced concreteness (the concrete being the living experience) is not to avoid abstractions (because they are indispensable), but to be mindful of the journey back to living concreteness, that is, back to organizational life as it is lived." (Hernes, 2014, p. 21). James March (1994, p. 11) alluded already to the value of decoupling present interpretation from representations based upon the past: "For the most part, the world is interpreted and understood today in the way in was interpreted and understood yesterday. Decision makers look for information, but they see what they expect to see and overlook unexpected things. Their memories are less recollections of history than constructions based on 
what they thought might happen and reconstructions based on what they now think must have happened, given their present beliefs." (quoted in Hernes (2014, p.41)).

Including mindful coping in the reappraisal of sensemaking and learning is also important for another reason. According to practice theory, as learning increases, the share of non-deliberate acting increases and the mediation of mental representations decreases (Dreyfus \& Dreyfus, 2005; Tsoukas, 2010). The issue that we see here is that the so-called "non-deliberate" action has been learned somehow and has been imprinted through being absorbed in a socio-material practice, thus relying on mental representations. The more proficient one becomes, the less the carrying out of the activity is relying on these mental representations; but this does not mean that the activity is totally non-deliberate, as at some point in time the action has been learned and imprinted in mental representations. Therefore it is important to be aware of our automatisms and to reflexively sense whether the spontaneous acting (imprinted through mental representations of that past) is still 'up to date' when the action is carried out now. For learning to continue, an embodied reflexive act ascertains that the 'spontaneous' action still makes sense. In a way, this interaction between 'absorbed coping' and 'mindful coping' allows for non-deliberate learning

Mindful coping, as opposed to both detached and absorbed coping, induces a quality of metaawareness: in detached coping, one is not aware that (s)he is detached from reality, in absorbed coping, one is not aware to be absorbed in activity, however, in mindful coping, one is aware of its quality of awareness. It is this meta-awareness that enables the occurrence of learning, by releasing the powerful grip of 'already institutionalised orders' in which sensemaking takes place and surfaces the fact that "our relationship with the everyday world is one of unquestioned habit into which we are thrown" (Holt \& Cornelissen, 2013, p. 2). It is through this release of the past that actors learn to make sense of the future as it emerges. Learning adopts a dialectical quality of deframing and reframing in order to allow "yet unknown perspectives and insights" (Clegg, et al., 2005 , p. 156) into sensemaking. The possibility of learning that unfolds between sensemaking grounded in detached and absorbed coping is supported by Clegg, et al. (2005, p. 156, italics in original): "there can thus be a learning that lies between randonnée and method, foolishness and rationality, improvisation and standardised programme; such learning follows an inventive and capricious route".

Reappraising sensemaking in this fashion furthermore transcends the episodic-continuous dichotomy (Weick, 2012) in the sense that sensemaking is continuous in its nature; happening in one form or another all the time, but episodic in terms of its phenomenal quality. It is precisely this complementarity of being both episodic and continuous that allows learning to occur at the intersections of sensemaking episodes, whereby, according to Dreyfus and Dreyfus (2005), learning is fostered and expertise developed during interruptions or breaches in the continuity of sensemaking. As Weick (2012, p. 146) phrases it: "(S)ensemaking is triggered when the availableness of ready-to-hand coping is interrupted and attention shifts to unready-to-hand occurentness. (...) As expertise increases, breaching decreases, and experts are able to keep going because the availableness in which they are immersed is broad and deep. More of the world is available and ready-to-hand. Even when there is a breakdown, it is more likely to remain 
contextualised (unready-to-hand) than to be stripped of context (present-at-hand)." Along these lines, learning occurs at the intersection of what Elkjaer (2004) defined as 'three ways' of learning: acquisition of knowledge (through detached coping), experience by participation (through absorbed coping), and inquiry via reflexive practice (through mindful coping).

The deepening of the prevailing sensemaking perspective thus opens up the temporal dimension of sensemaking, whereby detached coping carries the past into the future, absorbed coping pulls emergent futures into the present, and mindful coping absorbs the present as it unfolds in its 'now-ness'. Indeed, sensemaking grounded in detached coping is mediated by mental representations cultivated in the past and thus predominantly retrospectively oriented. Sensemaking grounded in absorbed coping is embedded in a forward-looking temporality: "To be immersed in a practice is to have a sense for how it will unfold - to practice is to anticipate" (Sandberg \& Tsoukas, 2014, p. 19). Being grounded in absorbed coping, sensemaking receives a 'dwelling' or 'immanent' quality, which Sandberg and Tsoukas (2014) refer to as 'immanent sensemaking'. Sensemaking grounded in mindful coping is embedded in a predominant present temporality or 'now-ness' that transcends the cognitive and linguistic sphere. Sandberg and Tsoukas (2014), from a phenomenological perspective, refer to this form of sensemaking as 'embodied sensemaking'.

As such, specifying different phenomenal qualities of sensemaking shifts the emphasis of retrospection to the 'agency of the present' in an active temporality, acknowledging that (1) "pasts and the futures are experienced in the present" and (2) "the present more than just includes the past and future, it shapes the past and future" (Hernes, 2014, p. 4). Bringing an active and ongoing temporality in the sensemaking perspective under the form of balancing retrospection and the living present, brings the "preparing for various future potentialities" (Hernes, 2014, p. 39) into the picture and allows for a more balanced temporal framing of sensemaking. There is clearly a temporal interdependency in conceptualizing sensemaking that has thus far been underrepresented in efforts to elaborate on the sensemaking perspective (Sandberg \& Tsoukas, 2014), a temporal interplay that has sharply been stated by Mead (1932:31): "The novelty of every future demands a novel past" (quoted in Hernes (2014, p.44).

Repositioning learning through phenomenal qualities of sensemaking, finally, implies links between (1) action and reflection, and (2) the individual and social. The action-reflection transition is reflected in the detached-absorbed modes of coping whereby the former focuses on detached conceptualizations (i.e. cognitive reflection), and the latter emphasizes unreflective doing and action. Both merge, however in the quality of mindful coping that is reflexive (as opposed to pure reflective). The individual-social transition occurs in the process of enacting whereby potentiality materializes into actuality through the process of commitment (Salancik, 1977; Weick, 1988) whereby actions become irrevocable and public.

In sum, learning becomes an oscillation between de-framing and re-framing (Westenholz, 1993) and subsequently a "transformation of the images of thought that organize our reality" (Clegg, et al., 2005, p. 156), achieved through the dynamic equilibrium between sensemaking grounded in detached, absorbed and mindful coping. This balancing act allows for developing and enacting a 
new order that fuels emerging and yet unknown capabilities, perspectives and possibilities of interesting times.

\section{Implications for managerial practice}

As we see it, the reappraisal of sensemaking and learning discussed in this article has three major implications for managerial practice. First, awareness of underlying assumptions of how complexity needs be 'managed', is a prerequisite for appreciating how meaning is constructed and how learning takes place. Second, being aware of one's sensemaking quality, 'new sources of ignorance' (Weick, et al., 1999) will enrich their repertoires of action capabilities or thoughtaction repertoires (Fredrickson, 1998). As such, by expanding one's perceptual field, a richer inventory of plausible actions is constructed, and a broader repertoire of interpretations is gradually developed, complementing dominant frames of reference. Third, broader phenomenal qualities of sensemaking enable a complicated understanding of organizing (Weick, et al., 1999) taking place 'in practice'. Organisational efforts to build a more fully developed cognitive infrastructure enable a deeper understanding of the complexity faced (Weick \& Roberts, 1993). This cognitive infrastructure thus allows organisational actors to comprehend what is really going on, regardless of the interpretive apparatus imposed by conceptual orders. As such, actors learn to deal with the equivocal mess in the becoming of organisational processes as well as to develop intuitive awareness (Korthagen, 2005; Sadler-Smith \& Shefy, 2007) in management learning.

\section{Some reflexive thoughts...}

Although we see clear potential in this reappraisal of sensemaking and learning for interesting times, we have to note some downsides and unintended consequences. First, dominant institutional logics (Thornton, Ocasio, \& Lounsbury, 2012) dictate the rules of how organisation takes place, stipulating dynamics of competition, change, innovation and organizing. These market-driven logics are predominantly grounded in managerialistic framings that put a premium on rational, detached modes of coping in ever-present efforts to control and reduce complexity. In this context, integrating different phenomenal modes of sensemaking is hard to implement, whereby the simplicity part of the simplexity line of thought is favored. Second, enacting a dynamic equilibrium between different phenomenal qualities of sensemaking risks easily to overemphasize one quality over the others in an effort to balance, resulting in negative or unintended consequences (see Table 1). For example, overemphasis on deliberate coping may lead to what Taleb (2008) refers to as "platonicity': "(the) tendency to mistake the map for the territory, privileging pure and well-defined forms over messier less tractable structures." (Chia \& Holt, 2009, p. 20). As a result, learning is severely constrained by actively discouraging critical reflexivity, leading to 'functional stupidity' (Alvesson \& Spicer, 2012). Overemphasis on absorbed coping may eventually lead to organisational inertia or 'organisational foolishness' (March, 1981) whereby action lacks any sense of focus or direction, eventually having organisations float in multiple directions, thereby discarding strategic plans as well as share- and stakeholder expectations. Overemphasizing mindful coping leads potentially to a sustained inability to organize, i.e. to carve stability out of temporal flux, and thus to disorganisation. All three excess situations thus prevent learning to occur. 


\section{Conclusion}

This article provides the scaffolding for a more holistic approach towards sensemaking and learning, by arguing that learning under conditions of dynamic complexity occurs through widening the aperture of the sensemaking perspective by taking in an interpretative phenomenological approach that takes process and temporality seriously. Adding further refinement to the simplexity line of thought, we infused different modes of relating to the world in the sensemaking perspective thereby transcending its predominant retrospective temporal orientation as well as the continuity-episodic tension that limits the further investigation of a more holistic and integrative sensemaking perspective.

This reframing adds to theorizing on sensemaking and learning in two ways. First, we elaborate on a broader temporal perspective of sensemaking that is grounded in the past, present and emerging future rather than being predominated by retrospectivity, and refine its continuityepisodic paradox by demonstrating that sense is continually made or re-enacted at the intersection of different phenomenal qualities. Second, we reappraise learning in times of dynamic complexity as occuring during the continuous re-enactment of sense being made at the crossroad of detached, absorbed and mindful coping, in an effort to both reduce and explore equivocality. "To learn (...) we must retrieve what we deliberately forgot" (Weick \& Westley, 1999, p. 197) which - in terms of the phenomenal qualities of sensemaking advanced in this article - implies blending detached, absorbed and mindful coping in order to allow those emerging futures which have been cut off by our frames of reference back in our perceptual field thereby revisiting and updating the frames that blinded us in the first place.

To conclude, our conceptualization of learning is in line with Colville, et al.'s (2014, p. 226) analysis that "one has to disrupt order to create order, therefore creating moments of learning by juxtaposing order with disorder and vexing them together": learning occurs through the continuous entwinement of reducing and exploring equivocality, of making sense through past conceptualizations, emerging potentialities and embodied reflexivity. Our answer to the question "But what if events do not remind you of a story? Is there still sensemaking?" (Colville, et al., 2012, p. 8) is: Yes, absolutely! Just like sense is made (cognitively) by placing cues in existing frames, sense is also enacted by pulling potentialities of emerging futures into the living present, unable to fit it within prefabricated frames and requiring a not-knowing reflexive attitude to create meaning and learn how to cope with it.

\section{Acknowledgements}

We are grateful to the three anonymous reviewers for their comments and as well as to the editors of this special issue for their guidance on improving the quality of draft versions of the paper.

\section{Funding statement}

This research received no specific grant from any funding agency in the public, commercial of not-for-profit sectors. 


\section{References}

Allard-Poesi F (2005) The paradox of sensemaking in organizational analysis. Organization 12(2): 169-196.

Alvesson M and Spicer A (2012) A Stupidity-Based Theory of Organizations. Journal of Management Studies 49(7): 1194-1220.

Blattner W (2006) Heidegger's' being and Time': A Reader's Guide. London: Bloomsbury Publishing.

Bourdieu P (1990) The logic of practice. Stanford: Stanford University Press.

Chia R (1996a) Organizational analysis as deconstructive practice. (Vol.77) Berlin: Walter de Gruyter.

Chia R (1996b) The Problem of Reflexivity in Organizational Research: Towards a Postmodern Science of Organization. Organization 3(1): 31-59.

Chia R (2013) Reflections: In Praise of Silent Transformation Allowing Change Through 'Letting Happen'. Journal of Change Management 14(1): 8-27.

Chia R and Holt R (2006) Strategy as practical coping: A Heideggerian perspective. Organization Studies 27(5): 635-655.

Chia R and Holt R (2009) Strategy without design : the silent efficacy of indirect action. Cambridge: Cambridge University Press.

Clegg SR, Kornberger M and Rhodes C (2005) Learning/becoming/organizing. Organization 12(2): 147-167.

Colville I (1994) Searching for Karl Weick and Reviewing the Future. Organization 1(1): 218224.

Colville I, Brown AD and Pye A (2012) Simplexity: Sensemaking organizing and storytelling for our time. Human Relations 65(5): 5-15.

Colville I, Hennestad B and Thoner K (2014) Organizing changing and learning: A sensemaking perspective on an ongoing 'soap story'. Management Learning 45(2): 216-234.

Colville I, Pye A and Brown AD (2013) Sensemaking and Learning for Interesting Times. Special Issue Call for Papers. Management Learning.

Cooper R and Law J (1995) Organization: Distal and proximal views. Research in the Sociology of Organizations 13: 237-274.

Csikszentmihalyi M (1992) Flow: The Psychology of Happiness. London: Rider.

Cunliffe AL (2002) Reflexive dialogical practice in management learning. Management Learning 33(1): 35-61.

Cunliffe AL (2004) On becoming a critically reflexive practitioner. Journal of Management Education 28(4): 407-426.

Cunliffe AL and Easterby-Smith M (2004) From reflection to practical reflexivity: experiential learning as lived experience. In: Reynolds $\mathrm{M}$ and Vince $\mathrm{R}$ (eds) Organizing reflection. Hampshire: Ashgate, pp. 30-46. 
Daft RL and Macintosh NB (1981) A Tentative Exploration into the Amount and Equivocality of Information-Processing in Organizational Work Units. Administrative Science Quarterly 26(2): 207-224.

Dewey J (1910/1997) How we think. New York: Courier Dover Publications.

Dreyfus HL (1991) Being-in-the-world: A Commentary on Heidegger's Being and Time División I. Cambridge: MIT Press.

Dreyfus HL and Dreyfus SE (2005) Peripheral vision expertise in real world contexts. Organization Studies 26(5): 779-792.

Elkjaer B (2004) Organizational learning the 'third way'. Management Learning 35(4): 419-434.

Farjoun M (2010) Beyond Dualism: Stability and Change As a Duality. Academy of Management Review 35(2): 202-225.

Fredrickson BL (1998) What good are positive emotions? Review of General Psychology 2(3): 300-319.

Heidegger M (1926/2010) Being and Time. New York: Suny Press.

Hernes T (2007) Understanding organization as process: Theory for a tangled world. London: Routledge.

Hernes T (2014) A Process Theory of Organization. Oxford: Oxford University Press.

Hernes T and Irgens EJ (2013) Keeping things mindfully on track: Organizational learning under continuity. Management Learning 44(3): 253-266

Hernes T and Maitlis S (2010) Process Sensemaking and Organizing: An Introduction. In: Hernes $\mathrm{T}$ and Maitlis S (eds) Process Sensemaking and Organizing. Oxford UK: Oxford University Press.

Holt R and Cornelissen J (2013) Sensemaking revisited. Management Learning doi: $101177 / 1350507613486422$.

Holt R and Sandberg J (2011) Phenomenology and Organization Theory. In: Tsoukas H and Chia R (eds) Philosophy and Organization Theory. Vol. 32 Emerald Group Publishing, pp. 215-249.

James W (1956) The will to believe. New York: Dover Publications.

Jordan S, Messner M and Becker A (2009) Reflection and Mindfulness in Organizations: Rationales and Possibilities for Integration Management Learning 40(4): 465-473.

Kabat-Zinn J (2003) Mindfulness-based interventions in context: past present and future Clinical psychology. Science and practice 10(2): 144-156.

Keevers L and Treleaven L (2011) Organizing practices of reflection: A practice-based study. Management Learning 42(5): 505-520.

Korthagen FAJ (2005) The Organization in Balance: Reflection and Intuition as Complementary Processes. Management Learning 36(3): 371-387.

Law J (2004) After method: Mess in social science research. London: Routledge.

Maitlis S and Christianson M (2014) Sensemaking in Organizations: Taking Stock and Moving Forward The Academy of Management Annals 8: 57-125. 
March JG (1981) Footnotes to Organizational Change. Administrative Science Quarterly 26(4): 563-577.

March JG (1991) Exploration and Exploitation in Organizational Learning. Organization Science 2(1): 71-87.

March JG and Olsen JP (1975) The Uncertainty of the Past: Organizational Learning under Ambiguity. European Journal of Political Research 3(2): 147-171.

Matsushita K (1994/2002) The heart of management. New York: PHP Institute.

Maturana HR and Varela FJ (1992) The tree of knowledge: the biological roots of human understanding. Boston: Shambhala.

O'Leary M and Chia R (2007) Epistemes and structures of sensemaking in organizational life. Journal of Management Inquiry 16(4): 392-406.

Ramsey C (2014) Management learning: A scholarship of practice centred on attention? Management Learning 45(1): 6-20.

Reynolds M (1998) Reflection and critical reflection in management learning. Management Learning 29(2): 183-200.

Sadler-Smith E and Shefy E (2007) Developing intuitive awareness in management education. Academy of Management Learning \& Education 6(2): 186-205.

Salancik GR (1977) Commitment and the control of organizational behavior and behaviour. In: Staw BM and Salancik GR (eds) New Directions in Organizational Behavior. Chicago: St Clair, pp. 1-54.

Sandberg J and Tsoukas H (2011) Grasping the Logic of Practice: Theorizing Through Practical Rationality. Academy of Management Review 36(2): 338-360

Sandberg J and Tsoukas H (2014) Making sense of the sensemaking perspective: Its constituents limitations and opportunities for further development. Journal of Organizational Behavior DOI: 101002/job1937

Scharmer CO (2009) Theory U: Learning from the Future as It Emerges. San Francisco: BerrettKoehler Publishers.

Schön DA (1983) The Reflective Practitioner: How Professionals Think in Action. New York: Basic Books.

Stacey R (2011) Strategic management and organisational dynamics: the challenge of complexity to ways of thinking about organisations (6th ed). Harlow England: Financial Times Prentice Hall.

Taleb NN (2008) The Black Swan: The Impact of the Highly Improbable. New York: Penguin Books Limited.

Thornton PH, Ocasio W \& Lounsbury M (2012) The Institutional Logics Perspective: A New Approach to Culture Structure and Process. Oxford: Oxford University Press.

Tsoukas H (2010) Practice strategy making and intentionality: a Heideggerian onto-epistemology for Strategy as Practice. In: Golsorkhi D, Rouleau L, Seidl D \& Vaara E (eds) Cambridge Handbook of Strategy as Practice. Cambridge: Cambridge University Press, pp. 47-62.

Tsoukas H and Chia R (2002) On organizational becoming: Rethinking organizational change. Organization Science 13(5): 567-582 
Tsoukas H and Hatch MJ (2001) Complex Thinking Complex Practice: The Case for a Narrative Approach to Organizational Complexity. Human Relations 54(8): 979-1013

Varela FJ, Rosch E and Thompson E (1992) The Embodied Mind: Cognitive Science and Human Experience. Cambridge: MIT Press.

Weick KE (1969) The social psychology of organizing. Reading Mass: Addison-Wesley.

Weick KE (1979) The social psychology of organizing (2d ed). Reading Mass: Addison-Wesley.

Weick KE (1995) Sensemaking in organizations. Thousand Oaks: Sage Publications.

Weick KE (2003) Theory and practice in the real world. In: Tsoukas H and Knudsen C (eds) The Oxford handbook of organization theory. Oxford: Oxford University Press, pp. 453-475.

Weick KE, Sutcliffe KM and Obstfeld D (2005) Organizing and the process of sensemaking. Organization Science 16(4): 409-421.

Weick KE (1988) Enacted Sensemaking in Crisis Situations. Journal of Management Studies 25(4): 305-317.

Weick KE (2002) Essai: Real-Time Reflexivity: Prods to Reflection. Organization Studies 23(6): 893-898.

Weick KE (2012) Organized sensemaking: A commentary on processes of interpretive work. Human Relations 65(1): 141-153.

Weick KE and Roberts KH (1993) Collective Mind in Organizations - Heedful Interrelating on Flight Decks. Administrative Science Quarterly 38: 357-381.

Weick KE, Sutcliffe KM and Obstfeld D (1999) Organizing for high reliability: Processes of collective mindfulness. Research in Organizational Behavior 21: 81-123.

Weick KE and Westley F (1999) Organizational Learning: Affirming an Oxymoron. In: Clegg SR, Hardy C and Nord WR (eds) Managing Organizations: Current Issues. London: Sage Publications, pp. 190-208.

Westenholz A (1993) Paradoxical thinking and change in the frames of reference. Organization Studies 14(1): 37-58.

Whitehead AN (2010) Process and Reality. New York: Free Press.

Wiebe E (2010) Temporal sensemaking: Managers' use of time to frame organizational change. In: Hernes $\mathrm{T}$ and Maitlis $\mathrm{S}$ (eds) Process sensemaking and organizing. Oxford: Oxford University Press, pp. 213-241.

Yanow D and Tsoukas H (2009) What is Reflection-In-Action? A Phenomenological Account. Journal of Management Studies 46(8): 1339-1364.

Zundel M (2013) Walking to learn: Rethinking reflection for management learning. Management Learning 44(2): 109-126. 